\title{
Risperidone for treating patients with dementia: systematic review of randomized, placebo-controlled clinical trials
}

\author{
Lon S Schneider \\ University of Southern \\ California, Los Angeles, \\ Department of Psychiatry and \\ the Behavioural Sciences, \\ Department of Neurology, \\ Keck School of Medicine, \\ Leonard Davis School of \\ Gerontology, 1510 San Pablo \\ St, HCC 600 \\ Los Angeles, CA 90033, USA \\ Tel.: + 13234427600 ; \\ Fax: +13234427601 \\ E-mail: lschneid@usc.edu
}

Keywords: Alzheimer's disease, atypical antipsychotics, clinical trials, dementia, risperidone

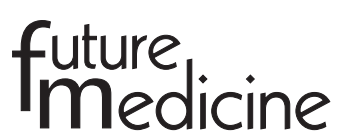

Context and Objective: The atypical antipsychotic risperidone is widely used to treat delusions, aggression and agitation in people with Alzheimer's disease and other dementia. In view of some clinical trials of atypical antipsychotics not showing efficacy in dementia and concerns about adverse events, the evidence for efficacy and safety of risperidone were reviewed. Literature Review and Study Selection: We searched the Cochrane Register of Controlled Trials (2005) and meetings presentations for published and unpublished clinical trials of risperidone to treat dementia patients. Other sources were searched; some reviews were selected as well. Outcomes and adverse events were tabulated, described and assessed. Results: Eight placebo-controlled trials of risperidone were identified (five unpublished); three did not have results available. The five included were 8-12 weeks in duration; one trial each also compared haloperidol and olanzapine (five comparator controlled trials were also identified). Approximately 1175 subjects were randomized to risperidone and 779 to placebo. Risperidone doses generally averaged $1 \mathrm{mg} /$ day (range 0.5 to $2.0 \mathrm{mg} /$ day). Overall risperidone reduced symptom severity to a greater extent than placebo. There was no overall difference from placebo in all-cause dropouts. The most common adverse events associated with risperidone in the placebocontrolled trials were sedation, edema, and extrapyramidal symptoms. There was no statistically significant increased risk for death or cerebrovascular adverse events (CVAEs) with risperidone overall. Conclusions: Clinicians who use risperidone to treat elderly patients with dementia should consider its use within the context of the medical need, the potential for increased risk of antipsychotics in general for serious adverse events such as CVAEs and deaths in mainly nursing home residents in clinical trials, medical comorbidity, and the efficacy and safety of alternatives.

The diagnostic criteria for Alzheimer's disease (AD) requires the presence of cognitive impairment, amnesia, disorientation, and other cerebral cortical deficits such as aphasia and apraxia [1]. Behavioural disturbances are common, however, occurring in the majority of patients during the course of their illnesses; psychotic features such as delusions and hallucinations are often prominent; aggression is common.

The prevalence of psychotic symptoms in patients with dementia varies between $10-73 \%$ with delusions and $21-49 \%$ with hallucinations [2]. In nursing home populations, at least $15-21 \%$ of newly admitted dementia patients may have delusions or hallucinations $[3,4]$. The proportion of dementia patients with psychosis is higher among those patients identified as agitated and in need of an antipsychotic medication; over three-quarters had significant delusions or hallucinations [5].

The 18-month prevalences in a populationbased sample of people with dementia over age
65 years was the following: $19 \%$ had delusions and $14 \%$ had hallucinations; and $6.5 \%$ and $2.6 \%$ had delusions or hallucinations, respectively, judged to be of moderate severity [6]. The incidences of delusions and hallucinations in this sample represented an annualized rate of 18 and $11 \%$, respectively [6].

In a dementia clinic sample (mean age 73 years, $49 \%$ women), the overall incidence of psychosis was $20 \%$ at 1 year, $36 \%$ at 2 years and $50 \%$ at 3 years [7]. In a clinical trials sample of mild-to-moderately impaired AD subjects (mean age 77 years, $62 \%$ women), $9 \%$ developed significant hallucinations or delusions after 5 months, and $12 \%$ had significant delusions or hallucinations at some time during the 5 months [8].

Overall, a substantial proportion of patients with psychosis have persistent symptoms over an indefinite period from at least 3 months to 1 year. Among nursing home patients with psychosis for at least 2 weeks $62 \%$ had persistent symptoms over at least 12 weeks [5]. Among 
out-patients who had significant delusions or hallucinations prior to treatment with placebo, $39 \%$ had persistent psychosis over 3 months and $33 \%$ over 5 months. In a 12 -month trial, $57 \%$ of out-patients with delusions or hallucinations at baseline had persistent symptomatology over the course of the year [9].

Moreover, the presence of psychosis has been associated with more rapid cognitive decline in patients with dementia [10-15], but may not be associated with increased mortality [16,17]. Treatment with antipsychotics and persecutory ideas have been associated with more rapid decline than those not treated or without persecutory ideas [10].

In conclusion, a majority of elderly patients with dementia develop aggression, delusions and other psychotic symptoms during their illness course. Conceptualization and criteria for a 'psychosis of dementia' or 'psychosis of Alzheimer's disease' has been proposed in order to more specifically identify these signs and symptoms as a distinct entity $[18,19]$.

\section{Antipsychotic treatment}

Antipsychotic medications have been frequently prescribed for psychotic features and aggression in dementia. During the last decade, the newer atypical antipsychotics (e.g., risperidone, olanzapine, quetiapine, and aripiprazole) have largely replaced the older conventional antipsychotics and have been considered preferred treatments for these behavioral disturbances [20,21], based partly on clinical trials evidence [22-26] and perceived relative safety advantages compared with other medications [20,21]. Until recently, about $30 \%$ of total prescriptions for atypical antipsychotics were for elderly patients in long-term care facilities in addition a substantial proportion of haloperidol use [27].

Haloperidol and thioridazine have been subjected to clinical trials in nursing home populations in the past, but subjects included had been heterogenous in terms of dementia diagnoses and behaviours [28]. Results from these trials generally suggested that antipsychotics conveyed a modest amount of efficacy, mainly on overall improvement, and with some adverse events. Haloperidol has been used as a comparator in recent placebo-controlled trials of atypical antipsychotics, generally showing roughly equivalent efficacy but with the expected extrapyramidal (EPS) symptoms [23,29].

A growing body of controlled clinical trials is gradually defining the efficacy of atypical antipsychotics in elderly patients with dementia.
The few published methodologically sound, placebo-controlled clinical trials, tend to enroll mainly nursing home patients with $\mathrm{AD}$ or vascular dementia, having agitation and other heterogeneous behaviors. Most of these trials remain unpublished some having been presented only as posters at scientific meetings [29,30].

Recently, there has been concern about increased risk for cerebrovascular adverse events (CVAEs, e.g., stroke and transient ischemic episodes) and deaths associated with atypicals [31-33,101]. Health Canada advised physicians 'to reassess the risks and benefits... in elderly patients with dementia... [and to] counsel their patients/caregivers to immediately report signs and symptoms of potential CVAEs ...' [34]. The US Food and Drug Administration (FDA) added warnings for increased CVAEs to the US prescribing information for risperidone in April 2003, olanzapine in January 2004, and aripiprazole in February 2005 [102-104]. In April 2005, the FDA issued a health advisory warning for increased risk for death with atypicals in people with dementia but did not provide data [105].

In this context we reviewed the evidence for risperidone's efficacy and adverse events in elderly dementia patients.

\section{Methods \\ Literature review \& selection}

For evidence for this review we searched the Cochrane Central Register of Controlled Trials (2005, Issue 1) [35], using the headings risperidone, dementia, and 'Alzheimer's disease.' We also searched available conference programs, abstracts, poster presentations, slides from medical meetings, and reviews. We selected trials that were parallel-group, double-blinded, placebo-controlled with random assignment to orally-administered risperidone or placebo and assessed efficacy and adverse events. Subjects had to be included because they had a dementia diagnosis, including $\mathrm{AD}$, vascular dementia, or mixed dementia. Trials did not need to be published and could be reported in other forms such as manuscripts, posters, abstracts, letters or slide formats. We also reviewed other trials that included dementia patients that were nonrandomized, used openlabel treatment or were comparator-controlled.

We noted trial features such as the presence of psychosis of dementia [18], medication doses, locations, trials durations, ages, gender, baseline cognitive scores, numbers randomized, outcomes, dropouts, and adverse events. 


\author{
Results \\ Search flow \\ The search yielded 61 citations from the \\ Cochrane database; 31 were retrieved as poten- \\ tial, controlled trials, from which 10 were \\ retained as fulfilling criteria. We also identified \\ five relevant non-published trials from other \\ sources including presentations at meetings and \\ from manufacturers (Table 1). \\ Eight placebo-controlled randomized controlled \\ trials were identified. Three were not included in \\ this review because of unavailability of data, includ- \\ ing a 4-week nursing home trial in Belgium (RIS- \\ BEL-14, $\mathrm{n}=39$ subjects), a 12-week multicenter \\ nursing home trial terminated early (RIS-INT-83, \\ $\mathrm{n}=18$ ), and a 12-week out-patient trial in Ger- \\ many using heterogeneous, not necessarily demen- \\ tia subjects with the vague diagnosis 'organic \\ psychosis syndrome' (RIS-GER-16, $\mathrm{n}=815$ ).
}

Six comparator controlled trials or studies comparing risperidone to other drugs but not to placebo were identified as well, including one that was not double-blinded, one crossover design; and one nonrandomized, open treatment trial with a 'no treatment' control group (Table 2). In addition, several long-term open-label studies and follow-ups to clinical trials were identified but not included.

\section{Trials and subject characteristics}

The five trials included in this review that fulfilled criteria as double-blind, placebo-controlled trials (Table 1) included one comparing risperidone to olanzapine and placebo in out-patients; four placebo-controlled trials in nursing homes, one with a haloperidol comparison. Four trials allowed dosage adjustment, one was dose-ranging, and three required fixed-doses. In the five trials we included,

\section{Table 1. Orally-administered placebo-controlled risperidone clinical trials.}

\begin{tabular}{|c|c|c|c|c|c|c|}
\hline $\begin{array}{l}\text { Ref./Study } \\
\text { code }\end{array}$ & $\begin{array}{l}\text { Key inclusion } \\
\text { criteria/location/trials } \\
\text { duration/sample size }\end{array}$ & Medication dose & $\begin{array}{l}\text { Age range, } \\
\text { years (SD) }\end{array}$ & $\begin{array}{l}\text { Gender } \\
(\% \mathrm{~F})\end{array}$ & $\begin{array}{l}\text { MMSE } \\
\text { (SD) }\end{array}$ & $\begin{array}{l}\text { Study } \\
\text { outcomes }\end{array}$ \\
\hline $\begin{array}{l}\text { Deberdt et al., } \\
(2004)[30](p) \\
\text { HGGU }\end{array}$ & $\begin{array}{l}\text { Dementia with hallucinations } \\
\text { or delusions ( } 78 \% \text { AD, } 5 \% \\
\text { VaD, } 17 \% \text { mixed) } \\
\text { /Output/10 weeks } / \mathrm{n}=434\end{array}$ & $\begin{array}{l}2.5-10 \mathrm{mg} / \text { day, } \\
\text { mean }=5.2 \mathrm{mg} / \text { day; } \\
\text { and risperidone } \\
0.5-2 \mathrm{mg} / \mathrm{day}, \\
\text { mean }=1.0 \mathrm{mg} / \text { day }\end{array}$ & $78.4(7.4)$ & 66 & $14.5(5.6)$ & $\begin{array}{l}\text { BPRS, CGI, } \\
\text { CMAI, NPI, } \\
\text { PDS }\end{array}$ \\
\hline $\begin{array}{l}\text { Brodaty et al., } \\
\text { (2003) [25] } \\
\text { RIS-AUS-05 }\end{array}$ & $\begin{array}{l}\text { Dementia with aggression, } \\
\text { MMSE } \leq 23,(58 \% \text { AD, } 29 \% \\
V a D, 13 \% \text { mixed }) \\
/ N H / 12 \text { weeks } / \mathrm{n}=345\end{array}$ & $\begin{array}{l}0.50-2 \mathrm{mg} / \mathrm{day}, \\
\text { mean }=0.95 \mathrm{mg} / \mathrm{day}\end{array}$ & $82.7(7.1)$ & 71 & $5.3(8.0)$ & $\begin{array}{l}\text { BEHAVE-AD, } \\
\text { CGI, CMAI, } \\
\text { FAST, MMSE }\end{array}$ \\
\hline RIS-BEL-14 & Dementia/NH/n = 39 & - & - & - & - & - \\
\hline RIS-GER-16 & $\begin{array}{l}\text { 'Organic psychosis } \\
\text { syndrome/Outpt/n = } 815\end{array}$ & - & - & - & - & - \\
\hline $\begin{array}{l}\text { DeDeyn et al., } \\
\text { (1999) [23] } \\
\text { RIS-INT-24 }\end{array}$ & $\begin{array}{l}\text { Dementia, MMSE } \leq 23 \\
\text { BEHAVE-AD } \geq 8 \text { ( } 67 \% \text { AD, } \\
26 \% \text { VaD, } 7 \% \\
\text { mixed)/NH/12 weeks/ } \\
n=344\end{array}$ & $\begin{array}{l}0.50-4 \mathrm{mg} / \mathrm{day}, \\
\text { mean }=1.1 \mathrm{mg} / \mathrm{day} ; \\
\text { haloperidol: } \\
0.50-4 \mathrm{mg} / \mathrm{day}, \\
\text { mean }=1.2 \mathrm{mg} / \text { day }\end{array}$ & $\begin{array}{l}81 \\
\text { Range, } \\
{[56-97]}\end{array}$ & 56 & $8.4(7.8)$ & $\begin{array}{l}\text { BEHAVE-AD, } \\
\text { CGI, CMAI, } \\
\text { MMSE, } \\
\text { MOSES }\end{array}$ \\
\hline $\begin{array}{l}\text { Katz et al., } \\
\text { (1999) [22] } \\
\text { RIS-USA-63 }\end{array}$ & $\begin{array}{l}\text { Dementia, MMSE } \leq 23 \\
\text { BEHAVE-AD } \geq 8(73 \% \text { AD, } \\
15 \% \text { VaD, } 12 \% \\
\text { mixed)/NH/12 weeks } / n=625\end{array}$ & $\begin{array}{l}0.5,1 \text {, and } 2 \mathrm{mg} / \mathrm{day} \\
\text { groups }\end{array}$ & $82.7(7.7)$ & 68 & $6.6(6.3)$ & $\begin{array}{l}\text { BEHAVE-AD, } \\
\text { CGI, CMAI, } \\
\text { MMSE }\end{array}$ \\
\hline RIS-INT-83 & $\begin{array}{l}\text { AD with psychosis, MMSE } \\
5-23 / \mathrm{NH} / 8 \text { weeks } / \mathrm{n}=18 \\
\text { terminated by the sponsor }\end{array}$ & $0.5-1.5 \mathrm{mg} / \mathrm{day}$ & - & - & - & - \\
\hline $\begin{array}{l}\text { Mintzer et al., } \\
(2004)[36](p) \\
\text { RIS-USA-232 }\end{array}$ & $\begin{array}{l}\text { AD with psychosis, MMSE } \\
5-23 / \mathrm{NH} / 8 \text { weeks } / n=473\end{array}$ & $\begin{array}{l}0.5-1.5 \mathrm{mg} / \mathrm{day}, \\
\text { mean: } 1.0 \mathrm{mg} / \mathrm{day}\end{array}$ & $83.3(7.3)$ & 77 & $13.2(5.0)$ & $\begin{array}{l}\text { BEHAVE-AD, } \\
\text { CGI }\end{array}$ \\
\hline
\end{tabular}

(p) indicates poster presentation at medical meeting.

AD: Alzheimer's disease; BEHAVE-AD: A rating scale for behavioral symptoms; MMSE: Mini-mental State Examination; NH: Nursing home; $n$ : Number randomized; VaD: Vascular dementia. 


\section{Table 2. Comparison of controlled trials of orally-administered risperidone.}

\begin{tabular}{|c|c|c|c|c|c|c|}
\hline $\begin{array}{l}\text { Ref./Study } \\
\text { code }\end{array}$ & $\begin{array}{l}\text { Key Inclusion } \\
\text { criteria/location/trials } \\
\text { duration/sample size }\end{array}$ & Medication, dose & $\begin{array}{l}\text { Age } \\
\text { range, } \\
\text { years (SD) }\end{array}$ & $\begin{array}{l}\text { Gender } \\
\text { (\%F) }\end{array}$ & $\begin{array}{l}\text { MMSE } \\
\text { (SD) }\end{array}$ & $\begin{array}{l}\text { Study } \\
\text { Outcomes }\end{array}$ \\
\hline $\begin{array}{l}\text { Fontaine et al. } \\
\text { (2003) [37]. }\end{array}$ & $\begin{array}{l}\text { Double-blind randomized, } \\
\text { parallel group/dementia/ } \\
\mathrm{NH} / 2 \mathrm{wks} / \mathrm{n}=39\end{array}$ & $\begin{array}{l}\text { Risperidone ( } 1.5 \mathrm{mg} / \text { day }) \\
\text { versus olanzapine } \\
(6.6 \mathrm{mg} / \text { day })\end{array}$ & 83 & 67 & 8.2 & $\begin{array}{l}\text { NPI, CGI, } \\
\text { BEHAVE-AD }\end{array}$ \\
\hline $\begin{array}{l}\text { Ellingrod et al. } \\
(2002) \text { [38]. }\end{array}$ & $\begin{array}{l}\text { 'Single-blinded, not } \\
\text { randomized/dementia/ } \\
12 \text { weeks } / n=19\end{array}$ & $\begin{array}{l}\text { Risperidone versus } \\
\text { olanzapine }\end{array}$ & 85 & 79 & 13.1 & BPRS \\
\hline $\begin{array}{l}\text { Sajatovicet al. } \\
\text { (2002) [39]. }\end{array}$ & $\begin{array}{l}\text { Randomized, open-label, } \\
\text { mixed psychosis } \\
\text { diagnoses/output/4 months/ } \\
n=554 \text { quetiapine and } \\
n=175 \text { risperidone }\end{array}$ & $\begin{array}{l}\text { Risperidone ( } 4.4 \text { mg/day) } \\
\text { versus quetiapine } \\
\text { (318 mg/day) }\end{array}$ & 45.4 & 49 & na & HAM-D \\
\hline $\begin{array}{l}\text { Chan et al. } \\
(2001)[40]\end{array}$ & $\begin{array}{l}\text { Double-blind } \\
\text { randomized/dementia } \\
\text { (AD or VD)/12 weeks/ } \\
n=58\end{array}$ & $\begin{array}{l}\text { Risperidone (0.90 mg/day) } \\
\text { versus haloperidol } \\
\text { (0.85 mg/day) }\end{array}$ & $80.5(8.2)$ & 72 & $\begin{array}{l}8.0 \\
(5.5)\end{array}$ & $\begin{array}{l}\text { BEHAVE-AD } \\
\text { CMAI }\end{array}$ \\
\hline $\begin{array}{l}\text { Suh et al. } \\
(2004) \text { [41] }\end{array}$ & $\begin{array}{l}\text { Double-blind, } \\
\text { crossover/dementia/18 wks/ } \\
n=120\end{array}$ & $\begin{array}{l}\text { Risperidone } \\
(0.5-1.5 \mathrm{mg} / \text { day }) \text { versus } \\
\text { haloperidol } \\
(0.5-1.5 \mathrm{mg} / \text { day })\end{array}$ & $80.9(8.2)$ & 80 & $\begin{array}{l}9.6 \\
(6.6)\end{array}$ & $\begin{array}{l}\text { BEHAVE-AD } \\
\text { CMAI }\end{array}$ \\
\hline $\begin{array}{l}\text { Meguro et al. } \\
2004 \text { [42]. }\end{array}$ & $\begin{array}{l}\text { AD patients with wandering } \\
\text { or aggression/'separated } \\
\text { into a risperidone group } \\
(n=20) \text { and non- } \\
\text { risperidone group } \\
(n=14) / \text { open } \\
\text { treatment/1 month }\end{array}$ & $\begin{array}{l}\text { Risperidone ( } 1.0 \mathrm{mg} / \text { day) } \\
\text { versus no treatment }\end{array}$ & $\begin{array}{l}78.5 \text { and } \\
77.1\end{array}$ & 79 & 12.2 & $\begin{array}{l}\text { BEHAVE-AD, } \\
\text { sleep time, } \\
\text { wandering time }\end{array}$ \\
\hline
\end{tabular}

Note: These studies are provided for completeness. Without a placebo group it cannot be determined whether either treatment is effective. No interferences on efficacy or safety can be made from the non-randomized, not double-blinded studies.

overall 1175 subjects were randomized to risperidone and 779 to placebo.

Overall $76 \%$ of all subjects had $\mathrm{AD}$; mean age per trial ranged from 78.4 to 83.3 years; and $56-77 \%$ were female. Trials were $8-12$ weeks in duration. The extent of cognitive impairment ranged from mild to severe with mean Mini Mental State Examination (MMSE) scores of the trials ranging from 5.3 to 14.5 on a 30 -point scale. For all the placebo-controlled trials diagnoses were made on a clinical basis except for RIS-USA-232 where DSM-IV R criteria were used to define AD.

Characteristics and outcomes of the five placebo-controlled trials are described below.

\section{RIS-USA-63}

This trial randomized 625 nursing home subjects with dementia to one of three doses of risperidone or placebo for 12 weeks [22]. Risperidone showed a modest benefit in reducing severity measures of agitation and psychosis with 1 and
$2 \mathrm{mg} /$ day doses (but not $0.5 \mathrm{mg} /$ day) compared with placebo. Adverse events were greater at $2 \mathrm{mg} /$ day than at lower doses. A secondary analysis of only patients with psychosis of dementia, indicated a specific improvement in psychotic symptoms with treatment, not merely an improvement in agitation. In this analysis, $1 \mathrm{mg} /$ day was maximally effective for delusions, while $2 \mathrm{mg} /$ day was more effective than $1 \mathrm{mg} /$ day for agitation, implying that lower doses of antipsychotics may be preferable for treating the psychosis.

\section{RIS-INT-24}

In RIS-INT-24, 344 similar subjects with dementia were randomized to a flexible dose of risperidone (average $1.1 \mathrm{mg} /$ day) or placebo for 12 weeks [23]. The outcomes were less clear: risperidone improved measures of agitation but not psychosis, while haloperidol produced little effect on agitation. Notably, although more subjects treated with haloperidol developed 
EPS than with risperidone both drugs were equivalently tolerated in terms of dropouts with somewhat more haloperidol patients staying in the trial.

\section{RIS-AUS-05}

In the RIS-AUS-05 trial, 345 Australian and New Zealand nursing home subjects with dementia, selected mainly for agitation and aggressive symptoms, were randomized to flexible oral doses (average $0.95 \mathrm{mg} / \mathrm{day}$ ) for 12 weeks [25]. Overall, there was improvement in agitation and psychotic symptoms. It was noted in this trial that there were more cerebrovascular adverse events occurring in the subjects treated with risperidone than placebo. Most of the subjects enrolled in these three trials had AD but a substantial minority had vascular dementia.

\section{Lilly trial HGGU}

The Lilly HGGU trial compared risperidone, olanzapine and placebo in 434 out-patients with $\mathrm{AD}$ and psychotic symptoms over 10 weeks initially [30]. Overall there were no significant differences in outcomes among the treatments.

RIS-USA-232

The RIS-USA-232 trial randomized 473 nursing home subjects with psychosis of $\mathrm{AD}$ to placebo or between 0.5 to $1.5 \mathrm{mg} /$ day of risperidone for 8 weeks [36]. There were no significant effects for risperidone on the primary efficacy changes on the Behavioral Pathology in Alzheimer's Disease Scale (BEHAVE-AD) psychosis and Clinical Global Impressions. There was a nominally significant effect for risperidone in a cognitively more severe subgroup with MMSE scores from 5 to 9.

These last two trials enrolled only subjects with $\mathrm{AD}$ and psychotic symptoms.

\section{Summary of efficacy outcomes}

The main efficacy scales for the placebo-controlled trials include primarily the BEHAVE-AD, its subscales and global ratings such as CGIs in four trials; the Cohen-Mansfield Agitation Inventory (CMAI) in three; and the Brief Psychiatric Rating Scale (BPRS) and Neuropsychiatric Inventory (NPI) in one.

The BEHAVE-AD was common to four of the five placebo-controlled trials. Inspection shows a rather moderately strong effect in favor of risperidone of about 4.5 points in RIS-AUS05. In RIS-USA-63 both $2 \mathrm{mg} /$ day and $1 \mathrm{mg} /$ day showed moderate effects and
$0.5 \mathrm{mg} /$ day showed no significant effect. By comparison, they were no significant effects in RIS-INT-24 and RIS-INT-232. In HGGU, the trial comparing risperidone with olanzapine, there were no significant effects of either drug compared to placebo on the caregiver-rated NPI and clinician-rated BPRS.

Considering the trials as a whole there was an overall effect on symptom reduction with the BEHAVE-AD in the trials that allowed mixed dementia and subjects with agitation. Three of these trials generally showed moderate effects of 2-4 points on the nurses'-rated CMAI total score as well. There was no evidence for symptomatic effects in the two trials that required subjects to have $\mathrm{AD}$ and psychosis.

Risperidone did not show differential efficacy from either haloperidol or olanzapine in two trials on the primary outcomes used

Response rates on the BEHAVE-AD (i.e., improvement of 30 or $50 \%$ from baseline) were available for three of the trials. The largest response effects were from RIS-AUS-05, 38 versus $21 \%$ risperidone versus placebo, respectively. Response rates were 54 versus $47 \%$ and 48 versus 33\% for RIS-INT-24 and RIS-USA-63, respectively. Available clincial global impression of change (CGIC) response rates from RISAUS-05 was $63 \%$ versus $37 \%$ and from RISINT-232 was $66 \%$ versus $56 \%$. These BEHAVE-AD response rates imply numbers needed to treat (NNTs) ranging from 6 to 15 , meaning that one patient may benefit for every 6 to 15 patients treated.

\section{Summary of adverse outcomes}

We counted $28.3 \%$ all-cause dropouts among risperidone-treated subjects and $28.0 \%$ among placebo-treated subjects. The most common adverse events occurring more often with risperidone than with placebo generally included somnolence or sedation, EPS, and edema. Available adverse event data from four trials are presented in Table 3. Evidence is that adverse events occur in a dose-related fashion. Somnolence was fairly consistent, occurring at 2-4-times that of placebo across the trials. Peripheral edema occured at a greater rate in some trials but not others; EPS occurs at 2-3-times the rate of placebo across the trials. The absolute rates of somnolence at $1 \mathrm{mg} /$ day ranged from 12 to $25 \%$, from 6 to $12 \%$ for EPS, and 5 to $12 \%$ for edema. There was no increase in injury or falls and a suggestion of actual decrease in rates with risperidone treatment compared to placebo. 
Table 3. Listing of available adverse events from risperidone placebo-controlled trials

\begin{tabular}{|c|c|c|c|c|c|c|c|c|c|c|}
\hline & \multicolumn{4}{|c|}{ RIS-USA- 63} & \multicolumn{2}{|c|}{ RIS-INT- 24} & \multicolumn{2}{|c|}{ RIS-AUS-05 } & \multicolumn{2}{|c|}{ RIS-INT-232 } \\
\hline & $\begin{array}{l}\text { Placebo } \\
\%\end{array}$ & $\begin{array}{l}0.5 \mathrm{mg} / \mathrm{ay} \\
\%\end{array}$ & $\begin{array}{l}1.0 \mathrm{mg} / \text { day } \\
\%\end{array}$ & $\begin{array}{l}2.0 \mathrm{mg} / \mathrm{day} \\
\%\end{array}$ & $\begin{array}{l}\text { Placebo } \\
\%\end{array}$ & $\begin{array}{l}\text { Risp. } \\
\%\end{array}$ & $\begin{array}{l}\text { Placebo } \\
\%\end{array}$ & $\begin{array}{l}\text { Risp. } \\
\%\end{array}$ & $\begin{array}{l}\text { Placebo } \\
\%\end{array}$ & $\begin{array}{l}\text { Risp. } \\
\%\end{array}$ \\
\hline Somnolence & 8 & 10.1 & 16.9 & 27.9 & 4.4 & 12.2 & 25.3 & 36.5 & 4.6 & 16.2 \\
\hline Falls & 20.2 & 16.1 & 12.8 & 24.8 & & & 27.1 & 25.1 & 12.6 & 11.1 \\
\hline EPS & 7.4 & 6.7 & 12.8 & 21.2 & 11 & 15 & 2.9 & 6 & 3.4 & 8.5 \\
\hline UTI & 12.9 & 16.1 & 12.8 & 21.2 & & & 14.7 & 23.4 & 10.1 & 9.4 \\
\hline Edema & 5.5 & 16.1 & 12.8 & 18.2 & & & 3.5 & 7.8 & 4.6 & 5.1 \\
\hline Purpura & 11.7 & 16.8 & 12.2 & 10.3 & & & 15.9 & 18 & & \\
\hline Agitation & 10.4 & 7.4 & 5.4 & 8.5 & & & 24.7 & 19.8 & 6.7 & 8.1 \\
\hline Injury & 37.4 & 32.9 & 28.4 & 31.5 & & & 37.1 & 35.9 & 10.5 & 9.4 \\
\hline Fever & 7.4 & 10.1 & 7.4 & 14.5 & & & 2.4 & 5.4 & & \\
\hline CVAES & $\star$ & * & * & * & * & * & 1.8 & 9 & 0.4 & 1.7 \\
\hline
\end{tabular}

*CVAEs were obtained directly from the publications for RIS-AUS-05 and RIS-INT-232. They were obtained from ref 30 and 33 for RIS-USA-63 ( 1 vs $1 \%$ ) and RIS-INT-24 ( 2 vs. 8\%, placebo versus risperidone, respectively);

EPS: Extrapyramidal signs; UTI: Urinary tract infection.

The adverse events occurring in HGGU were mainly available in relationship to treatment discontinuation. Here risperidone- (and olanzapine-) treated subjects were overall more likely to discontinue treatment due to a variety of adverse events than placebo subjects, 8.7, 16.3, and $3.2 \%$, risperidone, olanzapine and placebo, respectively. Somnolence was reported in 19, 23, and $9 \%$, and abnormal gait was reported in 11 , 10 , and $3 \%$, risperidone, olanzapine and placebo subjects respectively.

\section{Cerebrovascular adverse events \& mortality}

The present review revealed that Health Canada, the FDA, and the CSM all evaluated the occurrence of CVAEs [31-34,101]. The FDA analysis included six placebo-controlled trials (three unpublished) with 1009 risperidone-treated and 712 placebo-treated subjects and estimated a pooled relative risk of CVAEs with risperidone of 2.9, $95 \%$ confidence interval (CI), 1.3-6.2, after adjusting for several covariates.

With respect to deaths, we counted 45 deaths in 1175 risperidone-treated and 22 in 779 placebo-treated subjects, from five trials, a pooled incidence of 3.8 and $2.8 \%$ for risperidone and placebo respectively over the 8-12 week trials duration. The overall odds ratio for death in patients treated with risperidone compared with placebo was $1.30,95 \% \mathrm{CI}, 0.76-2.23, \mathrm{p}=0.35$.

\section{Summary of comparator-controlled trials}

Six comparator-controlled trials were identified (Table 2). Comparator controlled trials provide minimal, if any, evidence for efficacy or safety because of the lack of placebo control. It cannot be deduced whether either of the drugs or neither of them are efficacious, or whether one is superior to the other. Even when there is a statistically significant difference, either of the drugs may not be better than placebo or may be worse. They are included here for completeness.

In one double-blind parallel group trial over 14 days, 39 nursing home patients with dementia and agitation were randomized to olanzapine at initial doses of $2.5 \mathrm{mg} /$ day or risperidone at $0.5 \mathrm{mg} /$ day with titration to $10 \mathrm{mg}$ and $2 \mathrm{mg}$ allowed, respectively. At average doses of $6.6 \mathrm{mg} /$ day and $1.5 \mathrm{mg} /$ day of olanzapine and risperidone, respectively, both drugs improved global and NPI primary outcomes without any significant differences between them. Drowsiness or sedation and falls commonly occurred in both groups. Nearly half the patients in both groups had EPS at baseline that did not worsen.

In a single-blinded, nonrandomized trial in four nursing homes, 11 patients with $\mathrm{AD}$ or vascular dementia were treated with risperidone and 8 with olanzapine for 2 months. There were relatively more adverse events and decreases in blood pressure with olanzapine than with risperidone, but not other differences.

In a 4-month, multi-centered, open-label randomized trial 554 out-patients were assigned to quetiapine (mean $=318 \mathrm{mg} /$ day) and 175 to risperidone (mean $=4.4 \mathrm{mg} /$ day). Subjects could have a range of diagnoses, including schizophrenia, mood disorders, delusional disorders, and Alzheimer's and vascular dementia. There was a relatively greater 
improvement on Hamilton Depression Rating scores and less EPS in the patients treated with quetiapine, with a nonsignificant difference in incidence of EPS.

In a 12-week double-blind randomized comparison of haloperidol $($ mean $=0.90 \mathrm{mg} /$ day) and risperidone $($ mean $=0.85 \mathrm{mg} /$ day $)$, there were no significant differences between the two in clinical outcomes with haloperidol-treated patients showing worsening of EPS symptoms.

In an 18-week, double-blind crossover trial, 120 patients were randomly assigned to receive adjustable doses risperidone or haloperidol $(0.5$ to $1.5 \mathrm{mg} / \mathrm{d}$ ). In an analysis not adjusted for the crossover effects, patients on risperidone showed somewhat greater improvement on the BEHAVE-AD, after 8 weeks, and with less EPS than with haloperidol.

Finally, in one trial in $\mathrm{AD}$ nursing home patients who wandered and had aggression, subjects were divided into two groups - one treated openly with risperidone $(\mathrm{n}=20)$ and another not treated $(n=14)$. The patients were assessed for change in symptoms and in sleep and wandering times. Increased night-time and decreased daytime sleep was reported in the risperidonetreated subjects compared with those who received no treatment.

\section{Comment}

Taken together, the placebo-controlled risperidone clinical trials show efficacy over the course of the 8-12 weeks despite heterogeneity of outcomes. Outcomes in these trials were measured in terms of symptom reduction and clinicians' assessment of change.

However, not all trials demonstrated efficacy. Possible explanations for the lack of effect in RIS-INT-232 and in HGGU are that only patients with $\mathrm{AD}$ and psychosis were included for those trials, on average they had less cognitive impairment than subjects in the other trials, and the trials were of shorter duration, 8-10 weeks compared to 12 weeks. It is possible that risperidone is relatively more effective in treating agitation or aggression in more severely cognitively impaired patients than psychotic symptoms in relatively less severely impaired patients. The largest overall symptomatic effect size was in a trial in which nursing home subjects were selected in large part on the basis of showing significant aggressive behavior.

It is notable that in the two available comparisons with haloperidol and olanzapine under double-blind, placebo-controlled conditions, ris- peridone was neither superior to these drugs nor to placebo. Although methodologically flawed the comparator-controlled studies also did not show risperidone to be superior to other drugs.

Thus, there was heterogeneity of clinical response to risperidone possibly based on sample selection, duration of treatment duration, dose, and instruments used. The trials requiring that subjects have psychosis of $\mathrm{AD}$ showed less effect than the trials in patients with mixed dementia diagnoses who were selected because of aggression and agitation and were more cognitively impaired at baseline. The 4-week longer treatment durations were associated with significant improvements. The dose range tended to be limited with most subjects across placebo-controlled trials receiving $1 \mathrm{mg} /$ day so that potential benefits at higher or lower doses are not known. Finally, outcomes instruments were constrained to one instrument for all but one of the placebocontrolled trials, the BEHAVE-AD.

In interpreting these clinical trials the time course for response must be considered although only the outcomes at the end of the trial are formally statistically assessed. The trials did not include a provision for defining responders or time to response. At best, 'response' was gauged in a few trials by dichotomizing the BEHAVE$\mathrm{AD}$ generally at a $30 \%$ improvement point at the end of the trial, an inadequate definition of clinical response. But it is obvious in examining the several trend graphs included in the publications that there is generally substantial symptom improvement with both risperidone and placebo early on within the first 2-4 weeks, and that it is later beyond 8 weeks that mean differences between drugs and placebo become apparent.

This has important implications for clinical care, suggesting that the early substantial response may be due to in-study effects or improved psychosocial and environmental interventions. It also suggests that in patients who respond within this period of time, medication might be discontinued to assess whether the response is maintained as well as restarting medications in those whose symptoms get worse.

Only one trial was designed to assess doseresponse, in this case the mean change on the symptom scales. Here in rather severely cognitively impaired patients (mean baseline MMSE 6.6) there seemed to be a differential effect where improvement on psychosis symptoms were greater at $1 \mathrm{mg} /$ day while there was greater improvement on agitation measures at $2 \mathrm{mg} / \mathrm{day}$ at the cost of increased adverse events at $2 \mathrm{mg} /$ day. 
In this regard the extent of the significance the main adverse events of sedation, EPS, and edema are difficult to assess because severity is not also reported. The trials do not systematically report severity, duration, or whether intervention was required to treat the adverse events.

The potentially increased risk for CVAEs could be identified only when the atypicals were combined in metaanalyses. The risk difference of about $1 \%$ over the length of the trials is of clinical concern even as the kinds and severity of CVAEs are not adequately described, nor are risk factors known.

A recent FDA public health advisory reporting an increased risk for death with antipsychotics overall between 1.6 and 1.7 [105] adds to concerns about risk. The warning was based on a summary of clinical trials of several antipsychotics. There does not appear to be a significant effect however when deaths associated with risperidone alone are evaluated.

Assessments of the effects of age, gender, living status, or cognitive impairment ability to ambulate on clinical response can not be performed unless individual subject data are made available for metaanalyses. The placebocontrolled trials are similar enough that an individual subject metaanalysis might be able to identify characteristics with improvement. A metaanalysis may be particularly important considering that future large scale trials of risperidone are unlikely. The pharmaceutical manufacturer, the owner of most of these data, might be encouraged to allow their data to be combined and analysed by an independent organization without a material interest in the outcomes.

These findings indicate a need to consider certain changes in some clinical practice. Antipsychotics have been dispensed fairly frequently to patients with dementia and patients have been treated for long periods of times. The established risks for cerebrovascular adverse events with risperidone and an overall risk for death with atypical antipsychotics in general suggest that antipsychotics should be used with care. The fact that these events occur within 10 to 12 weeks of initiating medication, coupled with observations from individual clinical trials results that there is substantial improvement in both drug and placebo groups over the first one to four weeks lead to the suggestion that risperidone should be prescribed and dosage adjusted with the expectation of clinical improvement within that time. If improvement is not seen then the particular medication should be discontinued. Since a substantial proportion of patients responding may be responding to in-study effects, increased nursing care, environmental changes, or changes in medical status, and not actually to medication, attempts might be made to implement environmental or nonpharmacologic measures prior to beginning medication treatment, and ' $n$ of one' trials of medication withdrawal should be undertaken at frequent intervals to assess continuing need.

It is beyond the scope of this review of risperidone to discuss other pharmacologic alternatives. However, it should be considered that risperidone has been the best-studied psychotropic medication use for this purpose in terms of placebo-controlled trials, and there is a relative lack of efficacy and safety information for other medications. There are known and unknown risks involved with all medications, including other atypicals, as well as antidepressants and benzodiazapines where there is a dearth of efficacy and safety data.

\section{Future perspective}

There is a need for effective and adequately safe treatments for psychotic symptoms and aggression occurring in patients with dementia. Psychosocial and environmental treatments can be helpful but often are not effective. There is specificity and a continuing persistence of psychotic symptomatology among such patients. Most patients with psychosis continue to fulfill criteria for psychosis of dementia over at least 3 months, and over a half may have psychotic symptoms persist over a year. The substantial incidence of about $20 \%$ over a one year period suggests the need for prevention or prophylactic treatments.

Taken together, these trials suggest that risperidone is potentially effective in treating agitation and aggression symptoms of $\mathrm{AD}$ or dementia, and effective in treating psychosis symptoms in patients with agitation; but that treatment is not without risks. Considerably more work needs to be undertaken, with respect to sample selection, dosing, and assessing outcomes, safety, and overall effectiveness. Other antipsychotics may be effective as well but have not been as well studied. Prospectively designed trials, set out to reflect how drugs are used clinically, are needed to further confirm and describe the concept, clinical course and treatment responses. 
Executive summary

- Controlled trials of risperidone for dementia were reviewed.

- Eight placebo-controlled clinical trials in patients with dementia were identified, 3 with nursing home patients and 2 with out-patients -3 did not have results available. Only only of the available placebocontrolled trials specifically included patients with Alzheimer's disease, the others included dementia in general.

- Trials ranged from 8-12 weeks duration and median doses were generally $1.0 \mathrm{mg} /$ day.

- Overall, risperidone reduced behavioural symptoms more than placebo over the course of the trials. Two trials did not show a significant effect for risperidone.

- There were no differences in dropouts. The most common adverse events associated with risperidone were sedation, edema, and extrapyramidal symptoms, with sedation occurring at 2 to nearly 4 times the rate of placebo, and EPS about twice the rate of placebo. Cerebrovascular adverse events and deaths may be associated with risperidone use in dementia patients.

- Closer inspection of the trials shows that both placebo and risperidone-treated patients improved during the first few weeks of the trials, and risperidone-treated patients appeared to separate out from placebo after this time.

\section{Bibliography}

Papers of special note have been highlighted as either of interest $(\bullet)$ or of considerable interest $(\bullet)$ to readers.

1. McKhann G, Drachman D, Folstein M, Katzman R, Price D, Stadlan EM: Clinical diagnosis of Alzheimer's disease: report of the NINCDS-ADRDA Work Group under the auspices of Department of Health and Human Services Task Force on Alzheimer's disease. Neurology 34(7), 939-944 (1984).

2. Tariot P, Blazina L: The psychopathology of dementia. In: Handbook of Dementing Illnesses. Morris J (Ed.). Marcel Dekker, NY, USA 461-475 (1994).

3. Morriss RK, Rovner BW, Folstein MF, German PS: Delusions in newly admitted residents of nursing homes. Am. J. Psychiatry 147(3), 299-302 (1990).

4. Ballard CG, Margallo-Lana M, Fossey J et al:: A 1-year follow-up study of behavioural and psychological symptoms in dementia among people in care environments. J. Clin. Psychiatry 62(8), 631-636 (2001).

5. Schneider LS, Katz IR, Park S, Napolitano J, Martinez RA, Azen SP: Psychosis of Alzheimer's disease: validity of the construct and response to risperidone. Am. J. Geriatr. Psychiatry 11(4), 414-25, (2003).

6. Lyketsos CG, Steinberg M, Tschanz JT, Norton MC, Steffens DC, Breitner JC: Mental and behavioral disturbances in dementia: findings from the Cache County Study on Memory in Aging. Am. J. Psychiatry 157(5), 708-714 (2000).

7. Paulsen JS, Salmon DP, Thal LJ et al:: Incidence of and risk factors for hallucinations and delusions in patients with probable $\mathrm{AD}$. Neurology 54(10), 1965-1971 (2000).
8. Schneider L, Kershaw P: Evidence for the validity of psychosis of Alzheimer's disease. J. Neuro. Sci. 187, S141 (2001).

9. Levy ML, Cummings JL, Fairbanks LA, Bravi D, Calvani M, Carta A: Longitudinal assessment of symptoms of depression, agitation, and psychosis in 181 patients with Alzheimer's disease. Am. J. Psychiatry 153(11), 1438-1443 (1996).

10. McShane R, Keene J, Gedling K, Fairburn C, Jacoby R, Hope T: Do neuroleptic drugs hasten cognitive decline in dementia? Prospective study with necropsy follow-up. Br. Med. J. 314(7076), 266-270 (1997).

11. Chui HC, Lyness SA, Sobel E, Schneider LS: Extrapyramidal signs and psychiatric symptoms predict faster cognitive decline in Alzheimer's disease. Arch. Neurol. 51(7), 676-681 (1994).

12. Drevets W, Rubin E: Psychotic symptoms and the longitudinal course of senile dementia of the Alzheimer type. Biol. Psychiatry 25, 39-48 (1989).

13. Lopez O, Becker J, Brenner R, Rosen J, Bajaulaiye O, Reynolds C: Alzheimer's disease with delusions and hallucinations: neuropsychological and electrocephalographic correlates. Neurology 41, 906-912 (1991).

14. Stern Y, Albert M, Brandt J et al:: Utility of extrapyramidal signs and psychosis as predictors of cognitive and functional decline, nursing home admission, and death in Alzheimer's disease: prospective analyses from the Predictors Study. Neurology 44(12), 2300-2307 (1994).

15. Stern Y, Mayeux R, Sano M, Hauser W, Bush T: Predictors of disease course in patients with probable Alzheimer's disease. Neurology 37, 1649-1653 (1987).
16. Drevets WC, Rubin EH: Psychotic symptoms and the longitudinal course of senile dementia of the Alzheimer type. Biol. Psychiatry 25(1), 39-48 (1989).

17. Forstl H, Besthorn C, Geiger-Kabisch C, Sattel H, Schreiter-Gasser U: Psychotic features and the course of Alzheimer's disease: relationship to cognitive, electroencephalographic and computerized tomography findings. Acta Psychiatr. Scand. 87(6), 395-399 (1993).

18. Jeste DV, Finkel SI: Psychosis of Alzheimer's disease and related dementias. Diagnostic criteria for a distinct syndrome. Am. J. Geriatr. Psychiatry 8(1), 29-34 (2000).

- Discusses the concepts of psychosis of Alzheimer's disease

19. Laughren T: A regulatory perspective on psychiatric syndromes in Alzheimer's disease. Am. J. Geriatr. Psychiatry 9(4), 340-345 (2001).

- Discusses the regulatory perspective on providing labelling or licensing for drugs to treat behavioural symptoms in dementia or Alzheimer's disease.

20. Alexopoulos GS, Silver JM, Kahn DA, Frances A, Carpenter D: The Expert Consensus Guideline Series: Treatment of Agitation in Older Persons with Dementia. Postgrad. Med. 1-88 (1998).

21. Alexopoulos GS, Jeste DV, Chung H, Carpenter D, Ross R, Docherty J: The Expert Consensus Guideline Series: Treatment of Dementia and its Behavioural Disturbances. Postgrad. Med. 2005.

- An interesting exercise in which experts are asked to describe how they would treat patients with dementia and behavioural disorders under certain conditions. 
22. Katz IR, Jeste DV, Mintzer JE, Clyde C, Napolitano J, Brecher M: Comparison of risperidone and placebo for psychosis and behavioural disturbances associated with dementia: a randomized, double-blind trial. Risperidone Study Group. J. Clin. Psychiatry 60(2), 107-115 (1999).

- The first placebo-controlled clinical trial of risperidone and the template for subsequent trials.

23. De Deyn PP, Rabheru K, Rasmussen A et al.: A randomized trial of risperidone, placebo, and haloperidol for behavioural symptoms of dementia. Neurology 53(5), 946-955 (1999).

24. Street JS, Clark WS, Gannon KS et al: Olanzapine treatment of psychotic and behavioural symptoms in patients with Alzheimer's disease in nursing care facilities: a double-blind, randomized, placebocontrolled trial. Arch. Gen. Psychiatry 57(10), 968-976 (2000).

25. Brodaty $\mathrm{H}$, Ames D, Snowdon J et al.: A randomized placebo-controlled trial of risperidone for the treatment of aggression, agitation, and psychosis of dementia. J. Clin. Psychiatry 64, 134-143 (2003).

- This placebo-controlled clinical trial focused on patients with aggression; reported the largest effect size; nearly a third had vascular dementia; and a relatively large number of cerebrovascular adverse events were reported.

26. De Deyn PP, Carrasco MM, Deberdt W et al:: Olanzapine versus placebo in the treatment of psychosis with or without associated behavioural disturbances with Alzheimer's disease. Int. J. Geriatr. Psychiatry 19, 115-126 (2004).

27. Schneider L: Usage Patterns of multiple psychotropic medications in nursing home patients. Presented at: NCDEU, 42nd Annual Meeting 10-13 June, FL, USA (2002).

28. Schneider LS, Pollock VE, Lyness SA: A metaanalysis of controlled trials of neuroleptic treatment in dementia. J. Am. Geriatr. Soc. 38(5), 553-563 (1990).

- A meta-analysis of the first generation or conventional antipsychotics, mainly haloperidol and thioridazine, describing overall modest efficacy for the medications for treating patients with dementia and describing methodological limitations.

29. Tariot PN, Schneider LS, Katz IR, Mintzer JE, Street JS: Quetiapine in nursing home residents with Alzheimer's dementia and psychosis. 15th Annual Meeting American Association Geriatric Psychiatry, Orlando, Florida. 24-27 February. Am. J. Geriatr. Psychiatry 10(2), 93 (2002).

30. Deberdt W, Dysken MW, Rappaport SA et al.: Placebo-controlled comparison of olanzapine and risperidone in the treatment of psychosis and behavioural disturbances in patients with dementia. Presented at: American Geriatrics Society, 17-21 May, NV, USA (2004).

31. Wooltorton E: Risperidone (Risperdal): increased rate of cerebrovascular events in dementia trials. Can. Med. Assoc. J. 167(11), 1269-1270 (2002).

32. Wooltorton E: Olanzapine (Zyprexa): increased incidence of cerebrovascular events in dementia trials. Can. Med. Assoc. J. 170(9), 1395 (2004).

33. Racoosin JA: Evaluating a safety signal in the postmarking period: cerebrovascular adverse events associated with risperidone and olanzapine. Paper presented at: The 17th Annual Meeting of the American Association for Geriatric Psychiatry, 21-24 February, MD, USA (2004).

34. Anonymous: Risperdal warning letter. Health CanadaTherapeutic Products Directorate 11 October (2002).

35. Anonymous: The Cochrane Library. John Wiley \& Sons Ltd, Chichester UK 1 (2005).

36. Mintzer J, Weiner M, Greenspan A et al: Efficacy and safety of a flexible dose of risperidone versus placebo in the treatment of psychosis of Alzheimer's disease. Presented at: International College of Geriatric Psychopharmacology; 14-17 October, Basel, Switzerland (2004).

37. Fontaine CS, Hynan LS, Koch K, MartinCook K, Svetlik D, Weiner MF: A doubleblind comparison of olanzapine versus risperidone in the acute treatment of dementia-related behavioural disturbances in extended care facilities. J. Clin. Psychiatry 64(6), 726-30 (2003).

38. Ellingrod Vl, Schultz SK, Ekstam-Smith K, Kutscher E, Turvey C, Arndt S: Comparison of risperidone with olanzapine in elderly patients with dementia and psychosis. Pharmacotherapy 22(1), 1-5 (2002).

39. Sajatovic M, Mullen JA, Sweitzer DE: Efficacy of quetiapine and risperidone against depressive symptoms in out-patients with psychosis. J. Clin. Psychiatry 63(12), 1156-63 (2002).

40. Chan W, Lam L, Choy C, Leung V, Li S, Chiu H: A double-blind randomised comparison of risperidone and haloperidol in the treatment of behavioural and psychological symptoms in Chinese dementia patients. Int. J. Geriatr. Psychiatry 16(12), 1156-1162 (2001)

41. Suh G.H, Son H.G, Ju YS et al.: A randomized, double-blind, crossover comparison of risperidone and haloperidol in Korean dementia patients with behavioural disturbances. Am. J. Geriatr. Psychiatry 12, 509-516 (2004).

42. Meguro K, Meguro M, Tanaka Y, Akanuma $\mathrm{K}$, Yamaguchi K: MI Risperidone is effective for wandering and disturbed sleep/wake patterns in Alzheimer's disease. J. Geriatr. Psychiatry Neurol. 17(2), 61-7 (2004).

\section{Websites}

101 Anonymous: Medicines and Healthcare products Regulatory Agency letter. Summary of clinical trial data on cerebrovascular adverse events (CVAEs) in randomised clinical trials of risperidone conducted in patients with dementia 9 March 2004 medicines.mhra.gov.uk (Accessed July 2005)

102. Risperdal www.risperdal.com (Accessed July 2005)

103. Zyprexa www.zyprexa.com (Accessed July 2005)

104. Abilify www.abilify.com (Accessed July 2005)

105. Food and Drug Administration www.fda.gov/cder/drug/advisery/antipsycho tics.htm

(Accessed July 2005) 